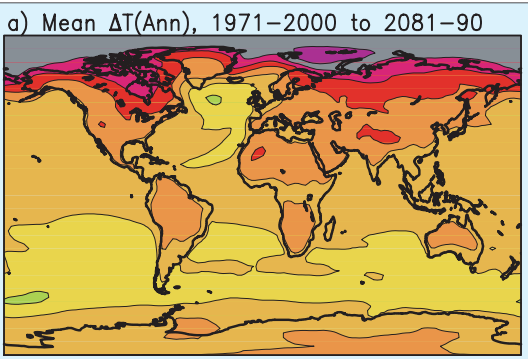

$\begin{array}{lllllll}1 & 2 & 3 & 4 & 5 & 6 & 7^{\circ} \mathrm{C}\end{array}$

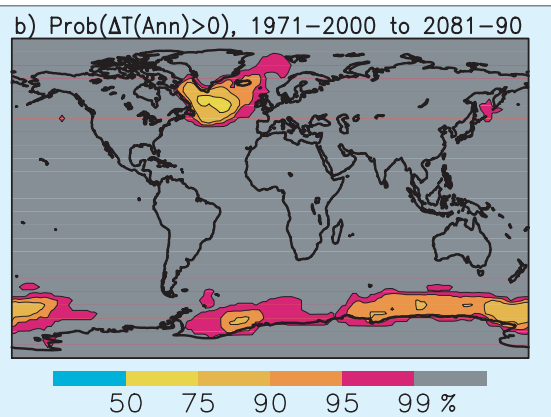

$50 \quad 75 \quad 90 \quad 95 \quad 99 \%$

Figure 1: A) Annual mean temperature change from 1971-2000 to 2081-2090, as averaged over 21 models forced with the SRES A1B emissions scenario. B) Estimated probability that temperature change exceeds zero. The relatively low probability in the northern North Atlantic is a result of models that simulate cooling due to changes in ocean circulation (Räisänen and Ruokolainen, 2006, Tellus A, 58).

be taken to curb human influence on the properties of the atmosphere.

A parallel program was also scheduled for approx. 50 high school students. These students were taken to a local peat bog where they were given an introduction to palaeoclimatology, which included the coring of peat, lake and marine sediments. This fieldtrip was followed by a "climate panel debate", in which the students were given the opportunity to ask scientists at the GeoBiosphere Science Centre about past, present and future climates. Lund is located only $20 \mathrm{~km}$ from the recently opened road-rail link to Copenhagen. It was, therefore, appropriate that the workshop ended with a visit to the Niels Bohr Institute to see the ice cores recovered from the Greenland ice sheet.

\section{AcKnowledgements}

The organizers are grateful to the British Council for their financial support and for the efficient management of the workshop by $\mathrm{Ki}$ Andersson (Sweden) and Michael SorensenJones (Denmark). We thank the participants and keynote lecturers for an intellectually intense and stimulating few days, and Sune Olander Rasmussen for his guided tour of the Niels Bohr Institute.

\section{IAN SNOWBall ${ }^{1}$, SvaNte BJöRck, RichaRd}

BradshaW, Keith BRIFFa, Richard Jones and MaRKKU RUMMUKAINEN

'Lund University, Sweden;

ian.snowball@geol.lu.se

\title{
New trends in Geomorphology - systems-based understanding of long term man-landscape interactions
}

\section{LUCIFS WoRKSHOP, MuenZENBERG, GermanY; 11-14 MAY 2006}

LUCIFS is a constitutive part of PAGES Focus 5 "Past Ecosystem Processes and Human-Environment Interactions". The LUCIFS research explores past to present responses of fluvial systems to climate change and human activities. After 2000, the LUCIFS group organized a second major workshop open to all interested members of the research community. The workshop focused on man-environment interactions, particularly on geomorphological and sedimentological perspectives on mid- to long-term quantitative sediment fluxes.

The meeting was convened in Muenzenberg near Frankfurt, Germany from 11-14 May 2006. The LUCIFS leader, Richard Dikau (Univ. Bonn, Germany), and the local organizers, Peter Houben (Univ. Frankfurt, Germany), Lothar Schrott (Univ. Salzburg, Austria) and Jürgen Wunderlich (Univ. Frankfurt, Germany) were very pleased to welcome 41 participants from 5 continents and 14 countries (Fig. 1). The workshop provided a stimulating working atmosphere with high-profile talks. The tight schedule consisted of 19 oral and 11 poster presentations, of

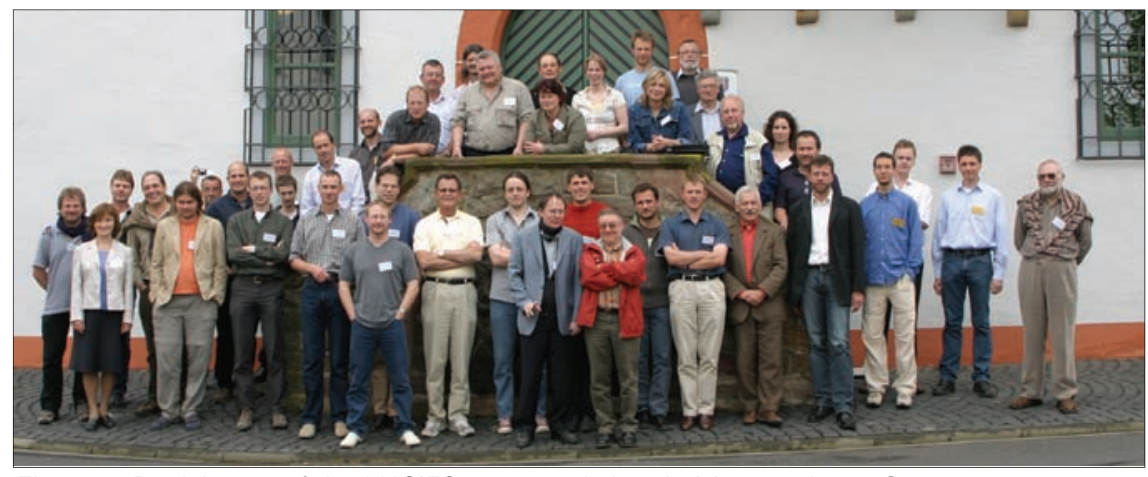

Figure 1: Participants of the LUCIFS 2006 workshop in Muenzenberg, Germany.

which 5 keynote talks considered the state of the art in various fields of man-environment research. All contributions were of outstanding quality and sparked animated discussions.

The workshop program was supplemented by a pre-workshop fieldtrip led by Peter Houben. During the fieldtrip, the methodical approach and results of a Holocene sediment budget study for Rockenberg catchment were presented. One of the main messages there was that in this area, the spatial pattern of erosion and redeposition, the routing of sediments and the changes in rates of flux and delivery along the sediment cascade have been chiefly controlled by human actions.
On Saturday afternoon, small working groups elaborated on selected topics of Holocene humanenvironment interactions. The 4 thematic foci were:

- Systems-based understanding of earth surface change with respect to Holocene sediment flux.

- Evaluating quantitatively human impact on earth surface systems.

- Exploring the sedimentary record: cross-cutting approaches to catchment-scale sediment flux.

- Coupling changing pressures of anthropogenic and natural drivers with modeling approaches.

Structured discussions helped to identify key issues for further re- 
search, which were presented to the whole group of participants in a succeeding plenary session. At least one of the small groups decided to edit a joint review paper based on the topics discussed during that afternoon.

Richard Dikau chaired the final plenary discussion on Sunday morning. His introduction dealt with the development of LUCIFS objectives and approaches over the past 6 years and included a critical review of past deficiencies. The discussions addressed future LUCIFS research strategies against the backdrop of the workshop contributions and current approaches to Earth System Science and will result in a revised LUCIFS research plan. Workshop contributions and results will be published in a special issue of Geomorphology (Elsevier). People interested in LUCIFS activities are invited to visit the PAGES Focus 5 homepage (www. pages-igbp.org/science/research/focus5.html) for further information.

\section{ACKNOWLEDGMENTS}

The Deutsche Forschungsgemeinschaft (DFG) gave considerable support by covering all workshop costs including staff appropriations for the large number of student helpers. PAGES co-sponsored the workshop by funding the travel costs of a number of participants from Eastern Europe and South America.

\section{Peter Houben}

Wolfgang Goethe University, Frankfurt, Germany; houben@em.uni-frankfurt.de

\section{Linkage between marine and terrestrial processes during past rapid climatic changes}

Barcelona, Spain; 13-15 March 2006

This workshop was organized by a new working group of the INQUA Commission on Coastal and Marine Processes. The group was inspired by our sadly missed colleague, Nick Shackleton, with the aim of analyzing paleoclimatic records from an integrated marine and terrestrial perspective. The objective of the workshop was to identify key scientific questions that could be addressed through future drilling/coring programs. New data sets from various regions (Fig. 1) were reviewed, and stimulated discussions on atmospheric and oceanic processes active in propagating and modulating past rapid climatic variability:

Zone 1: Sediment cores from the delta fan systems of the Congo Ogooué, Nyong and Sanaga rivers record changes in river discharge associated with latitudinal migration of the Intertropical Convergence Zone (ITCZ) over Africa during the last deglaciation and Holocene periods.

Zone 2: The evolution of the East African ITCZ was discussed on the basis of sediment cores from the Nile delta fan, which records changes in the hydrological regime of the Nile catchment regions.

Zone 3: The humidity evolution of North Africa and the interplay between low- and high-latitude processes during rapid climatic changes were discussed by

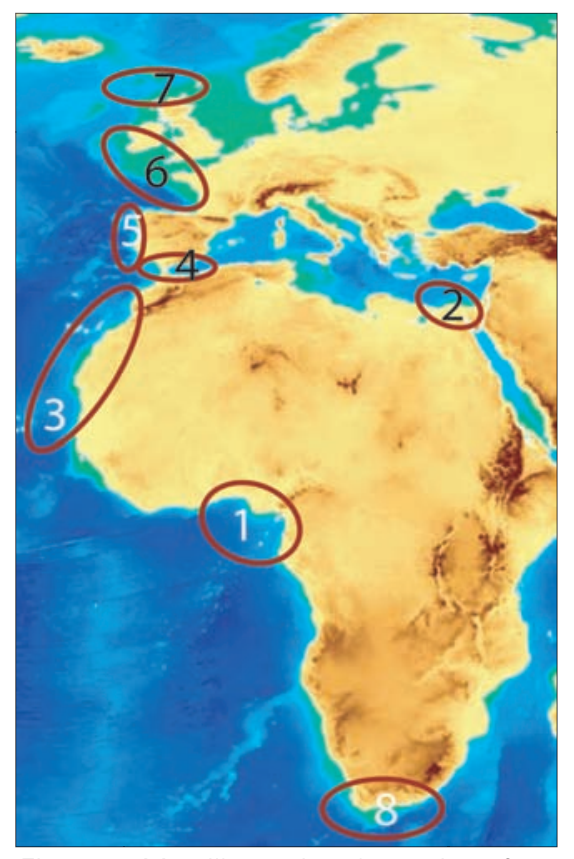

Figure 1: Map illustrating the regions from which data were presented and discussed during the workshop: (1) F. Marret and S.-Y. Kim; (2) S. Weldeab; (3) L. Dupont and O. Romero; (4) I. Cacho, F. Martinez, F. Lobo, L. M. Fernández-Salas, E. Llave and J. Hernandez-Molina; (5) F. Abrantes, T. Rodriques, L. Pena, C. Tzedakis and M. F. Sanchez-Goñi; (6) J. Scourse; (7) W. Austin and I. Hall; (8) I. Hall. Map Source: IHO-UNESCO, General Bathymetric Chart of the Oceans, Digital Edition, 2003, www.ngdc.noaa.gov/mgg/gebco (thanks to B. de Mol for data map processing).

means of new high-resolution records from around Cape Blanc and off Morocco.

Zone 4: Multi-proxy analyses of Alboran Sea sediments provide records of both marine and terrestrial processes at Dansgaard-Oeschger frequency. Geophysical data from shallow areas in the Gulf of Cadiz and
Alboran Sea were discussed for their potential in obtaining ultra-high resolution records. New data from the Gulf of Cadiz provided the basis for an IODP drilling proposal under evaluation.

Zone 5: The Western Iberian Margin is a unique area for marine-terrestrial linkage at centennial-millennial scale. New Holocene records off the Tagus River resolve decadal changes linked to the North Atlantic Oscillation (NAO). Holocene sediments from the Galician Rias record changes in the Meridional Overturning Circulation (MOC). Marine pollen records suggest different timing in the evolution of vegetation and sea level, providing an intriguing insight into the feedback mechanisms during glacial interceptions.

Zone 6: Sediments from the southwestern British Margin record the millennial-scale evolution of the British ice sheets (BIS). The role of the British Shelf in emitting or trapping atmospheric $\mathrm{CO}_{2}$ was discussed on the basis of model and proxy data of sea level, tidal dynamics and primary production.

Zone 7: The North British Margins provide sequences with extraordinary potential to study BIS sensitivity, and the interplay between surface oceanography and MOC. New records 